\title{
Entre la oscuridad y el silencio: Ciegos y sordomudos en el mundo de la Biblia
}

\author{
JUAN ALBERTO CASAS RAMíREZ \\ Pontificia Universidad Javeriana (Colombia) \\ jcasas.smsj@javeriana.edu.co
}

\begin{abstract}
Resumen
La condición de discapacidad es una realidad antropológica que no sólo afecta la integridad biológica de los individuos que la padecen sino también su interacción social y hasta su experiencia religiosa. Como una vía de aproximación a dicha realidad, el presente artículo propone un marco histórico-literario que permita comprender el trasfondo teológico de dos situaciones de discapacidad concretas, la ceguera y la sordera, a través de un estudio sobre tales condiciones en las tradiciones bíblicas y extra-bíblicas y en la literatura judía y greco-romana contemporánea a la redacción del Nuevo Testamento.
\end{abstract}

Palabras clave: Discapacidad en la Biblia, antropología bíblica, enfermedad en la Biblia, ceguera en la Biblia, sordera en la Biblia curación en la Biblia.

\section{Between darkness and silence: blind and deaf in the world of the Bible}

\begin{abstract}
The disability condition is an anthropological reality that affects not only the biological integrity of the individuals who suffer it but also their social interaction and even their religious experience. As a way of approach to such reality, this article proposes a bistorical and literary framework which leads to understand the theological background of two disabilities situations in specific, blindness and deafness, throughout a study about such conditions on the biblical and extra-biblical traditions and on the Jewish and Greco-Roman literature contemporary to the New Testament redaction.
\end{abstract}

Key words: Disability in the Bible, Biblical anthropology, Disease in the Bible, Blindness in the Bible, Deafness in the Bible, Healing in the Bible.

Candidato al Doctorado en Teología, Magíster en Teología y Licenciado en Ciencias Religiosas de la Pontificia Universidad Javeriana, Bogotá-Colombia. Profesor e investigador en el área de Teología Bíblica, Facultad de Teología, de la misma Universidad. Publicaciones recientes: Parábolas que siembran ceguera: Repercusiones del lógion de Mc 4,11-12 en la interpretación de la "parábola de la siembra" de Mc 4,1-20 (2015); La conversión como condición de posibilidad del seguimiento del Señor a partir del evangelio de Marcos (2013); La contingencia de la Palabra de Dios, presupuesto necesario de la bermenéutica bíblica (2012); “¿Dónde está tu Dios?” Apuntes para una reflexión teológica sobre la historia en los albores del siglo XXI (2012).

Recibido: 22/Noviembre/2015 - Aceptado: 21/Diciembre/2015 


\section{Introducción}

Es innegable que el Dios de Israel ha sido experimentado por el pueblo, desde sus más remotos orígenes, como aquel que está del lado de los oprimidos y busca su liberación (Andiñach, 2012: 116-117). Y si bien, dicha liberación ha sido entendida desde una perspectiva religiosa (liberación como salvación del pecado), socio-política (liberación como rescate de la injusticia social o de la opresión política) y hasta psico-somática (liberación como sanación de una dolencia física e incluso espiritual), las aproximaciones a este último modo de liberación se han centrado, la mayoría de veces, en su carácter milagroso o en su efecto salvífico sobre la persona sanada más que en el tipo de dolencia, en los individuos que la padecen, en las repercusiones de dicho padecimiento en el entorno social del enfermo y en las connotaciones religiosas de la enfermedad. El núcleo problemático de esta realidad radica en que en el trasfondo cultural de la Biblia Dios no solo es visto como aquel que libera de la enfermedad sino, al mismo tiempo, como aquel que la origina o, al menos, que permite que esta tenga lugar. Siendo así, ¿cómo entender que Dios libere de un padecimiento que él mismo ha propiciado? ¿Cuál puede ser el sentido teológico de la enfermedad cuando se considera que esta proviene de un Dios que se ha concebido como esencialmente misericordioso?

Son ya varias las investigaciones y reflexiones desarrolladas al respecto, no sólo desde la exégesis bíblica o la antropología cultural del mundo del Antiguo y del Nuevo Testamento, también desde la teología sistemática, la teología pastoral y hasta la teodicea. No obstante, el presente estudio quiere profundizar, desde un plano predominantemente exegético, en la comprensión de dos padecimientos en particular debido a su singular profusión a lo largo de las Sagradas Escrituras: estos son la ceguera y la sordera.

En efecto, las condiciones de ceguera o sordera en el mundo bíblico no se reducen simplemente a un estado de impedimento físico de quienes las padecen. Tienen implicaciones sociales (relacionadas con una realidad de exclusión y de vergüenza para quienes las padecen) e, incluso, teológicas (que remiten a Dios y sus designios sobre la historia como causa primera de dichas condiciones). Para profundizar en la complejidad pluriforme de estas realidades y teniendo como criterio rector el principio de unidad de toda la escritura, el presente artículo discurre alrededor de los campos semánticos de la ceguera y la sordera y realiza un rastreo panorámico de los diversos pasajes en que se menciona a ciegos o sordos de tal modo que se pueda dilucidar el sentido teológico que tradi- 
cionalmente era atribuido a estas condiciones en el mundo cultural y religioso tanto del Antiguo como del Nuevo Testamento.

\section{Trasfondo hermenéutico sobre la comprensión de la ceguera y la sordera en el Antiguo Testamento}

\subsection{Ciegos y ceguera en la TaNaKy en la Septuaginta}

En el Antiguo Testamento una de las fuentes principales para la comprensión teológica de la ceguera y la sordera se encuentra en los oráculos isaianos (especialmente Is 6,9-10), en los que el campo semántico de la ceguera registra la mayor recurrencia de todos libros del Antiguo Testamento (9 veces, en Is 29,18; 35,5; 42,7.16.18.19; 43,8; 59,10; 61,1). En la TaNaK, desde el Texto Masorético, la raíz עִ עue como sustantivo común traduce "piel" o "cuero" y como adjetivo traduce "ciego") se registra un total de 74 veces, de las cuales en 24 ocasiones tiene una función adjetival, es decir, indicando el carácter de aquellos que padecen de ceguera (Ex 4,11; Lv 19,14; 21,18; 22,22; Dt 15,21; 27,18; 28,29, 2Sa 5,6.8; Sal 145,8; Job 29,15; So 1,17; Mal 1,8, sin contar las referencias isaianas

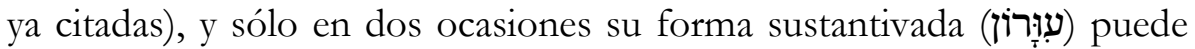
ser traducida literalmente como "ceguera" (Dt 28,28; Za 12,4). La Septuaginta (Rahlfs, 2006) usa el término $\tau \cup \phi \lambda o^{\prime}$ ("ciego") para traducir la

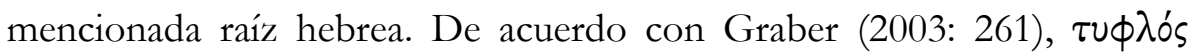
significa literalmente "obturado, tapado, impermeable (por ejemplo, en relación con desembocaduras, mares o abismos). En sentido activo significa propiamente invidente, ciego, y en sentido figurado, obcecado, ofuscado, espiritual y moralmente ciego. En sentido pasivo: inadvertido, escondido, tenebroso, oculto". De igual modo, la Biblia griega usa las formas sustan-

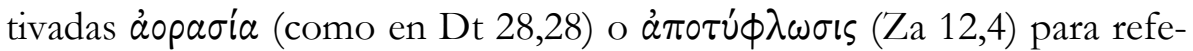
rirse al enceguecimiento, es decir, a la acción por la cual Dios dejará ciegos ya sea a aquellos que desoyen su voz y no practican sus mandamientos (Dt 28,15), o a los caballos de los gentiles (Za 12,4), en el marco de la restauración de Jerusalén en el post-exilio.

En torno a la situación social de los ciegos en el contexto cultural veterotestamentario y los señalamientos de los que son objeto, Estévez (1997: 325) afirma que "la ceguera es una de las enfermedades más comunes y extendidas en todo el mundo mediterráneo", mientras que Graber (2003: 161), por su parte, sostiene que,

la ceguera es relativamente frecuente en el oriente próximo; los rayos del sol, el polvo y la suciedad provocan la inflamación de los ojos, que puede 
llevar a la ceguera. La ceguera como castigo se menciona en Dt 28,28 ss en conexión con la gran maldición que amenaza al que quebranta la ley. La ceguera era una mácula desde el punto de vista cultural: los ciegos estaban excluidos del sacerdocio (Lv 21, 18), los animales ciegos no podían ser sacrificados (Lv 22,22; Dt 15,21)1. En el judaísmo tardío, la ceguera, dado que impedía al hombre el estudio de la Torá era considerada como un castigo de Dios (St.-B II, 193). Los ciegos -y los que tenían algún defecto físico- estaban excluidos de la comunidad de Qumrán (cfr. 1QSa I, 6; 1QM VI,4ss). El desamparo de las personas ciegas es proverbial (Dt 28,29; Is 59,9ss; Lm 4,14); dentro del pueblo son los más débiles y desdichados (esto se da a entender en $2 \mathrm{~S} 5,6-8)$; de aquí que estén bajo la especial protección de la ley $(\mathrm{Lv} 19,14$; Dt 27,18) y sean mencionados expresamente entre aquellos a quienes alcanza la salvación de Dios (Jer 31,8). El israelita piadoso está llamado a auxiliar a los ciegos $(\mathrm{Jb} 29,15)^{2}$.

Entre los personajes del Antiguo Testamento caracterizados por su ceguera se destacan los siguientes: Isaac, cuya condición es ocasión para ser engañando por su hijo Jacob (ver Gn 27,1-45) ${ }^{3}$ quien, a su vez, en los últimos años de su vida, también quedará ciego (ver Gn 48,10$)^{4}$. Sansón, cuya vida determinada por el deleite de su visión (ver Jc 14,1-2) contrasta con la dependencia a la que es sometido luego de la pérdida de sus ojos

1 “Cabe pensar que la razón última de estos impedimentos está en la sacralidad del sacrificio, lo que exige una apariencia de perfección física tanto por parte de los oficiantes como de los animales que se ofrecen a Yahvé” (León, 2011: 89-90).

2 Al respecto, León (2011: 90) complementa que "la Torá prohíbe maltratar al ciego y maldice a quien lo hace (Lv 19,14; Dt 27,18; véase Jb 29,15-16). En Lv 19,14 se protege al sordo incapaz de defenderse de las maldiciones que pudieran proferirse contra él, las cuales solían ser irrevocables y efectivas, independientemente de que fueran oídas o no, así como al ciego, que no puede ver los obstáculos que se pongan en su camino (Ex 22,21-26; Dt 27,18). No hay normas de este tipo, en favor de los discapacitados, en los códigos legales del antiguo Oriente Próximo”.

3 En tal sentido, Boase (2001: 321) afirma que Isaac es retratado como débil, confuso y manipulado por aquellos que están a su alrededor. En un momento, él reconoce que está hablando con el hijo equivocado (vv. 20-22.24), pero aun así bendice a Jacob y no a Esaú. Su decisión errónea tuvo lugar por haber confiado más en los sentidos del tacto (v.22), del olfato (v.27) y del gusto (v.4.25) que en la audición (v.22). Ello permitiría inferir una jerarquización de los sentidos de la percepción en que la visión y la audición estarían por encima de los demás sentidos (ver Lammers, 1967: 127). Irónicamente, Jacob, el que engañaba, acaba engañado por Labán, quien lo hace creer que se casa con Raquel pero, con la ayuda del velo, el banquete, la bebida y la

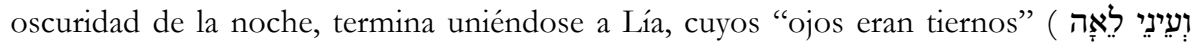
רַכּוֹת contraste con la belleza de Raquel (ver Gn 29,17). Al respecto, ver Hull (2007: 17).

4 No obstante, en el siguiente versículo $(48,11)$ su visión parece momentánea y milagrosamente restaurada por obra de Dios quien le concede ver el rostro de José y a los hijos de aquel. 
(ver Jc 16,21.26), razón por la que cobrará venganza (ver v.28). El sacerdote Elí (1S 3,2; 4,18), cuyas instrucciones dadas a Samuel ante la voz de Dios corresponden al modo como un vidente expresa su presencia y disposición de escucha hacia un invidente (ver 1S 3,9-10). El profeta Ajías de Silo $(1 \mathrm{R} 14,4)$ quien, a pesar de su ceguera, es capaz de reconocer a la reina, esposa de Jeroboam, al oír sus pasos $(14,6)$ y dirigirle un duro oráculo de parte de Dios (14,7-17). El rey Sedecías, enceguecido por el rey de Babilonia después de ver morir a sus hijos $(2 \mathrm{R} 25,7)^{5}$. En la Septuaginta, Tobit, quien queda ciego a causa del excremento de gorriones (Tb 2,10) pero atribuye esta calamidad a Dios y clama por su recuperación (3,3-6) recibiéndola, finalmente, gracias a la preparación recetada por parte del ángel Rafael a Tobías, el hijo de Tobit. Sobre este último caso, Hull (2007: 44) precisa con lucidez que,

Tobit, a pesar del carácter literal de su ceguera, es un símbolo de la nación exiliada. La imagen de la ceguera como metáfora de que el pueblo no comprende u obedece la alianza que hizo con Dios ya estaba muy establecida entre los profetas antes del exilio, de manera que una historia donde un representante ciego de Israel recupera la vista es una expresión simbólica de esperanza. El hecho de que la causa de la ceguera sea accidental, pero al mismo tiempo, de alguna manera sea parte de la providencia divina, está bellamente expresado en la historia de los excrementos de los gorriones; y expresa el sentido moral de Israel: a pesar de haber atraído ellos mismos el exilio y la destrucción de Jerusalén sobre sí, esto, no obstante, forma parte de los movimientos de la historia sobre los que ellos no tienen ningún control.

\subsection{Sordos y sordera en la TaNaKy en la Septuaginta}

Por su parte, la raíz חִ ("sordo"), traducida por la Septuaginta como $\varkappa \omega \phi o ́ s$, se registra un total de 125 veces en toda la $\mathrm{TaNaK}$ (en textos tales como Ex 4,11; Lv 19,14; Sal 37,14; 57,5; Hab 2,18; Is 29,18; 35,5; 42,18.19; 43,8; 44,116), 56 más que el campo semántico de la ceguera, aunque incluye también la actitud de guardar silencio. Y si bien la condición de sordera supone el de la mudez, ya que no es común que quien carezca del sentido de la audición pueda hablar (a no ser que haya perdido dicho sentido ya entrado en años), en el Texto Masorético se registra, además, la raíz אִ אִ ("mudo"), traducida con diversos matices por la Sep-

5 En contraste con los “ojos bellos" de David (1S 16,12), Sedecías, el último de su linaje real, termina en ceguera total.

6 La Biblia griega añadirá los pasajes de 3Mc 4,16 y Sab 10,21 a la lista de referencias sobre los sordos.

VERITAS, No 34 (Marzo 2016) 


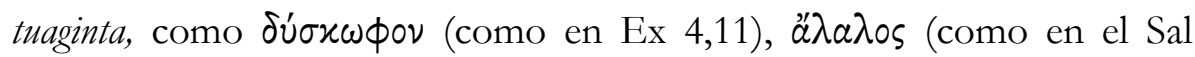

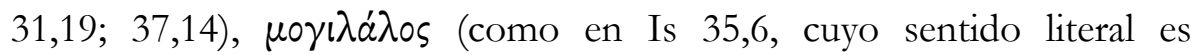
"impedido para hablar", "atado de la lengua" o "tartamudo") y દ́veós (como en Is 56,10, cuyo sentido literal es "impedido para hablar, generalmente a causa del temor o del estupor”). A dichos términos la

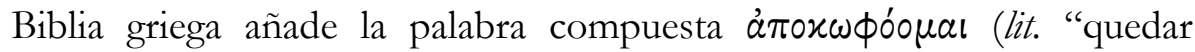
sordo/mudo" o "ensordecer/enmudecer"), usada en los oráculos de Ez 3,26; 24,27 para señalar el hecho de que es Dios quien produce o quita la sordera/mudez incluso en el profeta mismo (que es señalado por Dios con el título de "hijo del ser humano" en $24,16.25^{\circ}$ ) debido a la condición rebelde del pueblo que no le quiere escuchar. La menor recurrencia lexical de los términos relativos a la sordera y a la mudez en relación con los registros sobre la ceguera indica su carácter subordinado con respecto a la prelación que tenía la preocupación por la ceguera en el universo simbólico de Israel.

\subsection{Connotaciones teológicas de la ceguera y la sordera en el Anti- guo Testamento}

Resulta fundamental tener en cuenta que en siete ocasiones la ceguera y la sordera son mencionadas juntas (Ex 4,11; Lv 19,14; Is 29,18; 35,5; $42,18.19 ; 43,8)$, y de estas, en dos ocasiones la categoría de la mudez se añade a ambas (Ex 4,11; Is 35,5-6) para conformar una terna de situaciones de incapacidad que viene a señalar la condición de desgracia de aquellos que hacen parte de un pueblo cuyo principio identitario y fin último es "escuchar" la Torah (Dt 6,4), "ver" la gloria del Dios de la Torah (Dt 5,24; Ez 39,21; Is 66,18) y "proclamarlas" a las naciones (Dt 32,3; Sal $145,6)$.

De acuerdo con lo dicho, el texto de Ex 4,11 -el único de la Torah en el que es explícita la confluencia de los motivos de la ceguera, la sordera y la mudez- se presenta como el fundamento teológico que regirá la comprensión sobre la causa última de estas condiciones de incapacidad. Dicho texto hace parte del relato vocacional de Moisés (Ex 3,4-17) en el que, debido a la objeción interpuesta por el patriarca sobre su condición

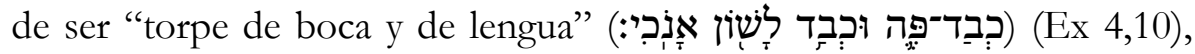

Este será el término usado por Marcos en 7,32.

8 Tal dato resulta pertinente para la comprensión marcana de Jesús como "Hijo del ser humano" cuyas parábolas pueden generar la ceguera de algunos que creen ver, y cuyas acciones son ocasión de restauración de la visión para los ciegos que (ya sea ellos o quienes interceden por ellos) reconocen su condición y claman por curación (fuera de la tradición marcana puede verse también Jn 9,39). 
Dios le responde a través de una serie de preguntas retóricas antitéticas que pretenden subrayar su carácter fontal tanto de la capacidad de hablar y de ver (aspectos positivos) como de la mudez, la sordera y la ceguera (aspectos negativos, en cuanto carencia de las facultades anteriores):

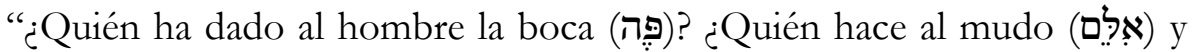

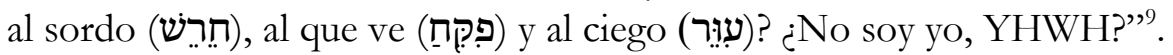

Ahora bien, si YHWH es la causa última de la ceguera y la sordera, no se puede desconocer la responsabilidad de Israel (como personalidad colectiva) al desarrollar estas incapacidades debido, especialmente, al abandono de la Alianza con YHWH y el consecuente recurso de la idolatría, tal como lo afirma De León (2011: 69): "La salud y la enfermedad se encuadran en el marco de la alianza de Yahvé con su pueblo Israel. La fidelidad a esta se convierte en fuente de salud para Israel; la infidelidad, por el contrario, en fuente de enfermedad y de todo tipo de desgracias, incluida la muerte prematura". De este modo, si la fidelidad a la Alianza produce el que el pueblo sea santo como YHWH es santo (ver Lv $11,44.45 ; 19,2 ; 20,7.26 ; 21,6)$, el olvido de la Alianza y el recurso a los ídolos ocasionan que el pueblo se haga igual que estos que "tienen boca, y no hablan; tienen ojos, y no ven; tienen oídos, y no oyen; tienen nariz, y no huelen; tienen manos, y no palpan; tienen pies, y no caminan; no emiten sonido alguno con su garganta" (Sal 115,5-7; ver también, Sal 135,16; Jr 5,21; Ez 12,2). Así, la relación mimética que existe entre un pueblo y su dios ocasiona que quien opta por los ídolos termine siendo igual que ellos, como señala el Salmo 115,8: "Se volverán como ellos, los que los hacen, y todos los que en ellos confían" (ver, también, Sal $135,18)$. Por tanto, sobre todo en las tradiciones proféticas de la $\mathrm{TaNaK}$, la ceguera y la sordera no serán más que el reflejo de la realidad del ídolo en la vida de quienes han optado por él.

De otra parte, el único texto de la $\mathrm{TaNaK}$ fuera de la Torah que reúne las categorías de la ceguera, la sordera y la mudez es Is 35,5-6, cuyo marco literario son los cantos de triunfo que anuncian el regreso del destierro a Jerusalén (Is 35,1-10) y se oponen a las sentencias pronunciadas contra Edom en el capítulo 34. Los signos escatológicos del regreso corresponden a la reivindicación de aquellos que han padecido discapaci-

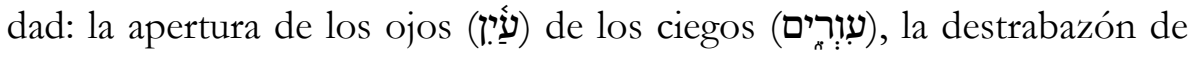

9 Recuérdese, al respecto, la ya clásica tipología estructural en las narraciones de la vocación de los profetas propuesta por Habel (1965), según la cual es común el surgimiento de una objeción o protesta por parte del profeta que es antecedida por una orden o reafirmación por parte de Dios. En este caso, la respuesta de Dios sería la frase introductoria de la orden.

VERITAS, No 34 (Marzo 2016) 


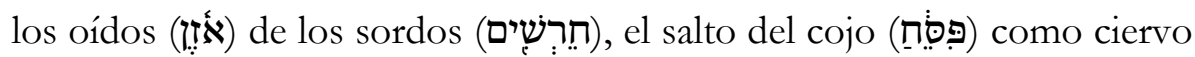

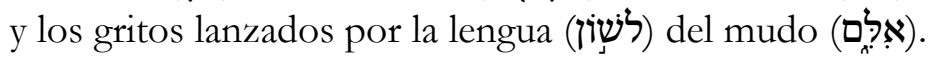

Nótese la relación que se establece entre el órgano de los sentidos, la mención de aquellos que carecen de dicho sentido y la acción que evidencia la restauración de dicho órgano. Al respecto, el análisis retórico que propone Meynet (2012: 73) de estos versículos y la relación dual que ofrece el Antiguo Testamento entre los ciegos y los cojos (puesto que el ciego, incapaz de ver el camino, no puede caminar sin ayuda) le llevan a afirmar que "el ciego (v.5) está cojo (6a) porque no ve el camino; el sordo (5b) está mudo (6b) porque no oye"10.

Es llamativo, además, que en el versículo que antecede la mención de los ciegos se registra la categoría del corazón acompañada por el mo-

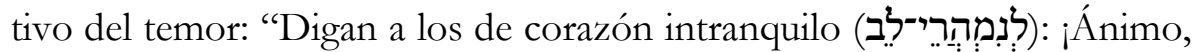
no temáis! (אל־תיראוֹ)" (Is 35,4). Dichas palabras de ánimo unidas al imperativo de no temer, además de ser transversales en el Antiguo Testamento, acompañando sobre todo los relatos de vocación profética ${ }^{11}$, serán comunes en los labios de Jesús cuando se enfrenta al miedo de sus seguidores $^{12} \mathrm{o}$ ante el desconsuelo de quienes le buscan por sanación $(5,36)$.

\section{Comprensiones sobre la ceguera y la sordera en el Nuevo Tes- tamento}

En el Nuevo Testamento los ciegos y los sordomudos hacen parte de un conjunto más amplio de personas oprimidas por las dolencias y las enfermedades entre las que se encuentran, además, los cojos y los leprosos. La especial atención de Jesús a este colectivo y la restitución de la salud que este les ofrece constituyen una señal inequívoca de la llegada de los tiempos mesiánicos en que las profecías veterotestamentarias alcanzan su cumplimiento. Como señala Schneider (2001b: 1812-1813), a los ciegos y a los sordomudos "se los menciona frecuentemente junto a los paralíticos $\left(\chi \omega \lambda \circ \mathbf{i}^{\prime}\right)$; ambos grupos de enfermos se consideraban espe-

10 Por tal motivo es correcto afirmar que, desde el marco veterotestamentario, "la curación de los ciegos y los sordomudos se promete, casi de modo exclusivo, para el tiempo de la salvación escatológica" (Schneider, 2001b: 1814).

11 Ver Gn 43,23; 50,19.21; Ex 14,13; 20,20; Nm 14,9; Dt 1,21.29; 3,22; 20,3; 31,6; Jos 1,9; 8,1; 11,6; Jc 6,23; 1Sa 12,20; 2R 25,24; 2Cr 20,15.17; Tb 12,17; 1Mac 3,22; 4,8; Is 7,4; 10,24; 13,2; 35,4; 37,6; 40,9; 51,7; 54,4; Jr 1,17; 10,2.5; 30,10 Sal 111,8; Ez 2,6; Neh 4,14 .

12 Ver Mt 10,26.28.31; 14,27; 17,7; 28,5.10; Mc 6,5; Lc 12,4.7.32; Jn 6,20. 
cialmente achacosos y desgraciados, sin esperanza alguna (cfr. Mt 11,5 y paralelos; Lc 7,22; Mt 15,30.31; 21,14; Lc 14, 13.21; Jn 5,3)”.

Así, en Mt 11,2-6 y su paralelo de Lc 7,18-28, ante la pregunta que hace Juan desde la cárcel sobre si Jesús es "el que ha de venir" o se debe esperar a otro, la respuesta de Jesús, más que afirmativa o negativa, remite a sus obras que permiten, a su vez, ser reconocidas como las señales esperadas de la llegada del eschaton. En términos de Graber (2003: 262), "Jesús da a entender que en su actuación y en su obra se ha hecho presente la salvación allí prometida y que ha hecho irrupción la era paradisíaca, en la que ya no habrá ceguera o sordera alguna": "Vayan y cuenten

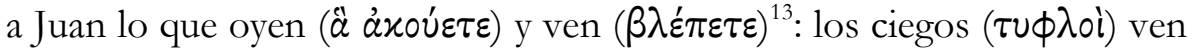

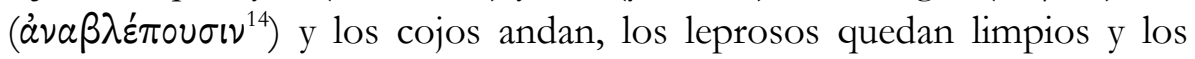
sordos ( $\varkappa \omega \phi \circ i)$ oyen (áxov́ov pobres el evangelio" (Mt 11,4-5: Lc 7,22). En la respuesta de Jesús, aunque se inserta el motivo de la limpieza de los leprosos, resulta innegable el marcado trasfondo isaiano, señalado por Allison (2000: 109) a través del siguiente esquema:

$\begin{array}{lll}\text { Ciegos ven } & \text { Is } 29,18 & \text { "Los ojos de los ciegos verán" } \\ & \text { Is } 35,5 & \text { "Se abrirán los ojos de los ciegos" } \\ & \text { Is } 42,7 & \text { "Para abrir los ojos ciegos" } \\ & \text { Is } 42,18 & \text { "Ciegos, miren y vean!" } \\ \text { Cojos andan } & \text { Is } 35,6 & \text { "El cojo saltará como el ciervo" } \\ \text { Sordos oyen } & \text { Is } 29,18 & \text { "Oirán los sordos" } \\ & \text { Is } 35,5 & \text { "Se abrirán los oídos de los sordos" } \\ \text { Muertos resucitados } & \text { Is } 26,19 & \text { "Revivirán tus muertos" } \\ \text { Evangelio predicado } & \text { Is } 61,1 & \text { "Me ha enviado a anunciar el evangelio } \\ \text { a los pobres } & & \text { a los pobres" }\end{array}$

De acuerdo con Dunn (2009: 517), en dicha respuesta se encuentra también un sorprendente eco de 4Q521 en que se habla de un Mesías futuro y de un reino eterno, "y en esa conexión se refleja la misma serie de pasajes de Isaías: devolución de la vista a ciegos, curación de tullidos, resurrección de muertos y predicación de la buena noticia a los pobres":

... [los cielos] y la tierra escucharán a su Mesías... Porque el Señor tendrá en consideración a los piadosos (basidim) y llamará a los justos por su nombre, y su espíritu se cernirá sobre los pobres, y dará nuevas fuerzas a los fieles con su poder. Porque glorificará a los piadosos en el trono de un reino

13 En la versión lucana estos verbos se encuentran en indicativo aoristo: a $\varepsilon$ हi $\delta \varepsilon \tau \varepsilon$ xai

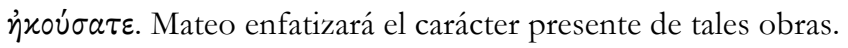

14 Literalmente, "reciben la visión".

VERITAS, No 34 (Marzo 2016) 
eterno. Él, que libera a los cautivos, devuelve la vista a los ciegos, endereza a los encorvados... Y el Señor realizará hechos gloriosos como jamás los ha habido (...). [Porque] curará a los heridos, resucitará a los muertos y predicará la buena noticia a los pobres (Dunn, 2009: 517).

Marcus (2010a: 563) por su parte, constata que,

El motivo de la apertura de los oídos aparece en los textos judíos como un símbolo de la revelación. El salmista de Qumrán alaba a Dios porque ha abierto sus oídos de manera que así puede escuchar misterios maravillosos (1QH 1,21). En esa misma línea, el Targum interpreta la apertura de los oídos de los sordos en Is 35,5 como un gesto que capacita al pueblo para escuchar las palabras de los profetas.

Volviendo al campo de los registros lingüísticos, en Mateo, el grupo de personas lisiadas que acuden a Jesús en busca de salud entre las que se mencionan a los ciegos y a los mudos vuelve a aparecer en 15,30-31 en el relato que precede la segunda multiplicación de panes: "Y se le acercó mucha gente trayendo consigo cojos, lisiados, ciegos, mudos y otros muchos; los pusieron a sus pies, y él los curó. De suerte que la gente quedó maravillada al ver que los mudos hablaban, los lisiados quedaban curados, los cojos caminaban y los ciegos veían; y glorificaron al Dios de Israel”. Nótese que la curación no ocurre como un fin en sí mismo sino que el maravillarse $(\theta a \nu \mu a ́ \zeta \omega)$ de la gente ante tales prodigios se convierte en

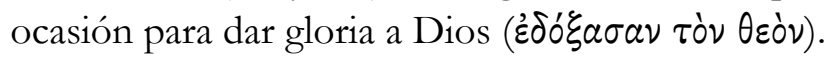

De igual forma, en Mateo, aunque ya no se mencione a los sordos y a los mudos, resulta importante el parangón que se establece entre 21,14, en el contexto de la expulsión de los vendedores del Templo $(21,12-17)$ en que una vez este es "purificado" se acercan algunos ciegos y cojos que son curados por Jesús-, y $2 \mathrm{Sa} 5,8$, en que se señala que una vez conquistada Jerusalén por parte de David este afirma que los ciegos y los cojos son aborrecidos, y el narrador agrega que este es el origen del dicho: "Ni cojo ni ciego entrará en la Casa”. De este modo, mientras el Mesías David, al conquistar Jerusalén, expulsa a los cojos y los ciegos de "la Casa", el Mesías Jesús, a su entrada a Jerusalén, a "la Casa", expulsa a los mercaderes pero acoge y sana a quienes fueron aborrecidos por el Mesías Da$\operatorname{vid}^{15}$.

15 En palabras de Sicre (2011: 59), el texto "nos sitúa ante dos hechos: uno, admitido por la institución religiosa, que es la presencia de mercaderes y cambistas; otro, rechazado por la misma institución, la presencia de cojos y ciegos: Jesús invierte las cosas: rechaza lo admitido, admite lo rechazado". 
Resultará igualmente importante el contexto de comensalía de Lc 14,12-24 en que Jesús pide a quien lo ha invitado que cuando ofrezca un banquete llame "a los pobres, a los lisiados, a los cojos y a los ciegos" $(14,13)$. Dentro del mismo marco narrativo, en la parábola sobre el banquete, que viene inmediatamente después, ante la inasistencia de los invitados, el dueño pide a su siervo que salga a las plazas y calles de la ciudad y haga entrar "a los pobres y lisiados, y ciegos y cojos" (14,21). En tales textos, si bien no hay referencia a la curación de los ciegos se señala otra característica identitaria de la irrupción del Reino, como lo es la inclusión de los más débiles y marginados en un ámbito comunitario igualitario cuya mejor expresión se manifiesta en el acto de sentarse a la mesa a comer juntos (recuérdense, al respecto, las palabras de Pablo en torno a la justicia social inclusiva que debe caracterizar la Cena del Señor en 1Cor 11,17-34) (Graber, 2003: 262).

Por otra parte, la mención de los lugares en los que el siervo encontrará a los pobres, lisiados, ciegos y cojos (plazas y calles de la ciudad) señala el carácter marginal y paupérrimo de su realidad ya que mientras los espacios sociales de los ciudadanos, tanto ricos como sencillos -iy hasta los esclavos!- son los palacios, las casas, los campos de cultivo y los talleres, quienes no poseen bienes deben resignarse a tener como espacio de representación las plazas y las calles, muy seguramente para pedir limosna y despertar la compasión e indulgencia de los aldeanos (ver Mc 10,46). En tal sentido, Estévez (2004: 209) afirma que "fuera de las murallas de la ciudad, a lo largo de los caminos y a las puertas de las casas de los ricos y del Templo vivía una población marginada. Las calles de las ciudades y sus sendas hacia fuera demuestran la distribución socioeconómica de la población y el tipo de intercambios que se producen". Ello evidencia, además, la relación entre la enfermedad y las condiciones sociales de quienes la padecen.

\subsection{Rastreo de campos semánticos en el Nuevo Testamento}

\subsubsection{Campos semánticos sobre ciegos y ceguera}

Con respecto al campo semántico específico de los ciegos, de acuer-

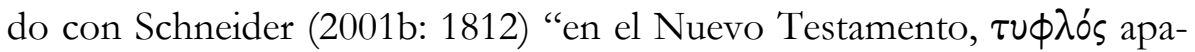
rece 50 veces, 46 de ellas en los Evangelios (17 en Mateo, 5 en Marcos, 8 en Lucas, 16 en Juan). Fuera de los evangelios, el término aparece únicamente en Hch 13,11; Rm 2,19; 2Pe 1,9; Ap 3,17”. Quienes padecen de ceguera, "engrosan los sectores más desfavorecidos e indefensos de Israel. Los evangelios nos los presentan mendigando por los caminos (Mt 
20,29-34; Mc 10,46-52; Lc 18,35-42)" (Estévez, 1997: 329) ${ }^{16}$. Ello implica que la condición del ciego no se reduce simplemente a su estado de carencia fisiológica del sentido de la visión sino que tiene también serias repercusiones socio-culturales que, en el contexto de Israel, se ven agravadas por las consideraciones tradicionales en torno a la causa de tal situación. Así, como aduce Estévez (1997: 329), "la vinculación entre pecado y ceguera es reflejada claramente por el evangelio de Juan $(9,1 \mathrm{ss})$. Aunque su defensa está prevista por la ley (Lv 19,14; Dt 27,18), su enfermedad, como otras malformaciones físicas es una falta irreparable que les excluye del sacerdocio ( $\mathrm{Lv}$ 21,16-24). Su cuerpo imperfecto no es digno de presentarse ante el Santo de los santos". Además, como señala Marcus (2010b: 873), si según algunos manuscritos de Qumrán la ceguera es considerada como una contaminación que excluye al que la tiene de ser miembro de la comunidad escatológica (1QT 45,12-14; 4QMMT B 49-54; 1QSa 2,3-10) y 11QTemplo 45,12-13, basándose en Lv 21,18; 22,22, prohíbe a los ciegos entrar a Jerusalén, la ciudad en la que mora Dios, para evitar que resulte profanada, el hecho de que ciegos curados, como Bar Timeo, sigan a Jesús en el camino hacia la Ciudad Santa (Mc 10,52) muestra el carácter escatológicamente inclusivo y "descontaminante" de la acción sanadora de Jesús (Olyan, 2001).

No obstante, como se evidencia en algunos pasajes de los evangelios y en todas las citas que no hacen parte del corpus narrativo del Nuevo Testamento (Rm 2,19; 2Pe 1,9; Ap 3,17) las referencias escriturísticas a la ceguera no sólo hacen relación a la dimensión fisiológica de la misma sino que remiten también a su carácter metafórico. De hecho, como indica Graber (2003: 262),

Cuando Jesús, en Mt 15,14 llama a los fariseos «guías ciegos», el término tiene aquí un sentido metafórico. Al igual que Pablo en Rm 2,19, alude con ello a la autoconciencia de los judíos letrados que reivindicaban para sí el título honorífico de $\delta \delta \eta \gamma o i ́$ $\tau \cup \phi \lambda \tilde{\omega} \nu$ (guías de ciegos), ya que se consideraban a sí mismos como los únicos guías legítimos de los paganos «ciegos», a los

16 No obstante, la ceguera no conducía necesariamente a la pobreza. Al respecto, Estévez (2004: 208) afirma que "la ceguera no tiene por qué traer como consecuencia una pérdida del estatus social, porque la posición social, ante todo se hereda, viene de nacimiento y está ligada a la sangre". Es documentado, a ese respecto, el caso del “cónsul Apio Claudio Caecus, que construyó antes de su ceguera el primer acueducto y la Vía Apia en Roma, y del que se recuerda un discurso en el Senado, ya siendo ciego, convenciendo a los romanos de no concluir el tratado de paz con el general griego Pirro; igualmente, Lucio Celio Metelo del año 243 al 221 a.C., aun estando ya ciego, desempeñó el cargo de Pontificex Maximus; y el general corintio Timoleón, quien después de ciego, continuó gozando de prestigio y de influencia política en Siracusa" (Estévez, 2004: 208). 
que habían de comunicar la luz del conocimiento y de la verdad. La ceguera de los fariseos no inspira a Jesús ninguna piedad, sino más bien provoca su condena, ya que manifiesta una actitud obstinada (cfr. Mt 23,16ss. 19.26; 16,4).

Al respecto, Guijarro (2000: 108) considera que el ciego era una representación simbólica de aquellos que no podían guiar a otros (ver Mt 15,15; 23,16-24; Lc 6,39; Rm 2,19). Además, "El ojo" podía ser una fuente de escándalo (ver Mt 5,29; Mc 9,47) o de deseo (ver Mt 5,27-28; 1Jn 2,16) e incluso un instrumento para perjudicar a otros (ver Mt 6,2223 ; 20,5). Los ojos cerrados expresan la incapacidad para entender (ver Mt 13,15; Lc 24,16) mientras que los ojos levantados eran signo de comunicación con Dios a través de la oración (ver Lc 16,23; 18,15; Jn 6,5; 17,1).

De igual modo, varios escritos del entorno cultural judío y grecoromano son testigos del uso figurado de la ceguera, como señala Schnei$\operatorname{der}(2001 b: 1814)$ :

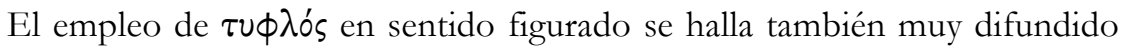
fuera del Nuevo Testamento; se refiere casi siempre -incluso fuera de la Biblia (cfr. Is 43,8; 59,10) y del judaísmo (cfr. CD 1,9; 16,2)- al ámbito del conocimiento (religioso) y de la función de entender (verdades religiosas). En la gnosis se designa como «ciegos» principalmente a los no-gnósticos, que se hallan irredentos y que están cegados por el mundo (EvVer 29, 2230, 15; EvTom 28; EvFel 56; Pistis Sophia 141).

Esta perspectiva simbólico-metafórica de la ceguera -entendida también como la obturación de la visión del misterio o de realidades de fe, causada, en ciertas ocasiones, por la acción de Dios- tendrá un papel relevante en la obra lucana. Así, por ejemplo, en el relato de Emaús (Lc 24,13-35) se señala que la razón por la cual los discípulos no reconocieron a Jesús es que "sus ojos estaban retenidos" (v.16: oi $\delta \dot{\varepsilon}$ ó $\phi \theta a \lambda \mu o i$

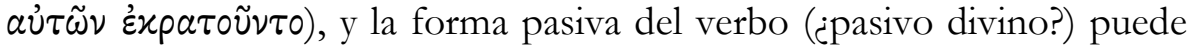
indicar que ellos no son los responsables directos de dicha incapacidad sino que se puede deber al designio de Dios. Ello queda confirmado en el v.31 por la descripción sobre el modo como finalmente reconocieron a

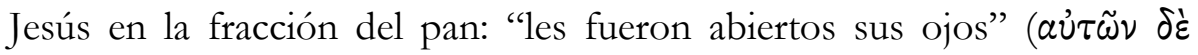
$\delta$ invoí $\chi \eta \eta \sigma \alpha \nu$ oi ó $\phi \theta a \lambda \mu o i)$, también en forma pasiva. Llama la atención que el reclamo que les dirige Jesús en el camino (v.25) traiga a colación el estado del corazón de aquellos: "Lentos de corazón" ( $\beta p a \delta \varepsilon i \tilde{\varsigma} \tau \tilde{n}$ xapdía), reafirmando la relación entre la ceguera y cierta "condición cardiaca". 
De igual modo, dentro de la narrativa de la segunda parte de la obra Lucana, además de la ceguera (de origen divino y con carácter punitivo) que recae sobre Elimas Bar Jesús (ver Hch 13,6-11), ocupará un lugar destacado el enceguecimiento de Saulo narrado en Hch 9,13-19 y recontado por el mismo Pablo lucano a los judíos de Jerusalén en 22,6-16 y luego ante el rey Agripa en 26,12-18. Como acota Wilson (2014), de su situación de poder y autoridad, Saulo pasa a una situación de dependencia y pérdida de control sobre su propio cuerpo que culmina con la pérdida de su visión. Y a pesar del mandato de Jesús de levantarse en 9,6 $\left(\dot{a} \nu a ́ \sigma \tau \eta \theta_{l}\right)$, Saulo sólo puede hacerlo con la asistencia de otros (sugerido

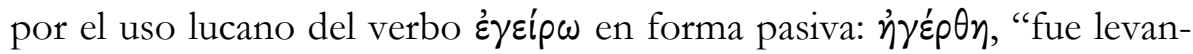
tado") y requiere ser llevado de la mano hasta Damasco (ver Hch 9,8) donde estará a merced, en total pasividad y vulnerabilidad, de Ananías, uno de los "seguidores del camino" a quienes persigue ${ }^{17}$, para recuperar su visión (ver Hch 9,10-19) ${ }^{18}$. Tales contrastes muestran la relación entre visión-poder/autonomía y ceguera-debilidad/dependencia. A partir de ese momento, el Pablo lucano entenderá su misión como obrar en los gentiles lo mismo que hizo Jesús en él: abrirles "los ojos, para que vuelvan de las tinieblas a la luz" (16,17-18; ver, también 28, 25-28).

\subsubsection{Campos semánticos sobre sordos, mudos, sordera y mudez}

A diferencia de las abundantes referencias a los ciegos en el contexto neotestamentario, la enunciación de los campos semánticos específicos de los sordos y los mudos resulta ser mucho menos frecuente. Solamente en el evangelio según Marcos se narra la curación de un hombre "sordo"

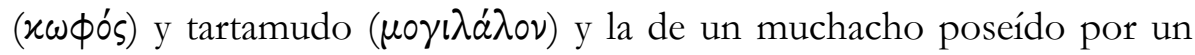

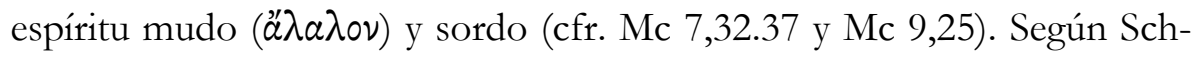

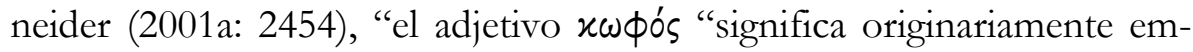
botado, obtuso; y puede referirse al órgano de la fonación o al de la audición, y por tanto puede significar tanto mudo como sordo". De modo semejante, Marcus (2010a: 554-555) afirma que el sentido original de la palabra $x \omega \phi \dot{\phi} \nu$ “es 'embotado' o 'torpe'. Probablemente no es casual que en Mc 7,31-37 el sordo sea un pagano, dado que los paganos se encuen-

17 Como Saulo, Ananías también tendrá que pasar por un proceso de "conversión" (no en el sentido estricto de paso de ser no-creyente a ser creyente o de una religión a otra, sino de "apertura de horizontes de comprensión de la realidad") para poder reconocer en su persecutor y victimario a un hermano, elegido por el Señor, que necesita de su mediación para recobrar la visión y ser bautizado (ver Hch 9,13-18).

18 Al igual que con Tobit (ver Tb 11,12), la recuperación de la visión de Saulo es narrada como una caída de escamas de los ojos (ver Hch 9, 18). 
tran relacionados con la sordera en diversos pasajes del Antiguo Testamento (Is 42,17-19; 43,8-9; Miq 7,16), por su presunta insensibilidad ante la Palabra de Dios".

En Mateo, inmediatamente después de la curación de dos ciegos (en 9,27-31, que con toda probabilidad une en un solo relato el doblete Marcano del ciego de Betsaida de Mc 8,22-26 y del ciego Bar Timeo de 10,46-52), en 9,32-33 se narra la curación/exorcismo de un hombre mu-

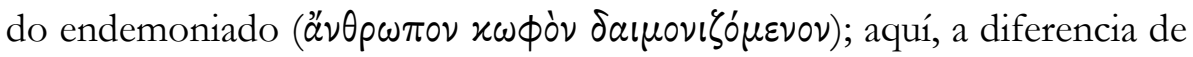
Mc 9,25 en que el espíritu es el sordo, el hombre presenta dos padecimientos, es él quien está sordo y, además, está poseído. Además, en Mt 12,22 se describe el caso más crítico de todo el Nuevo Testamento ya

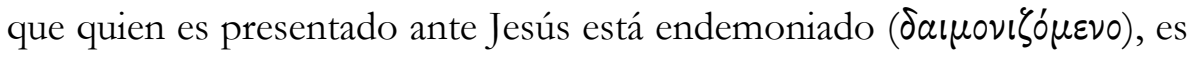

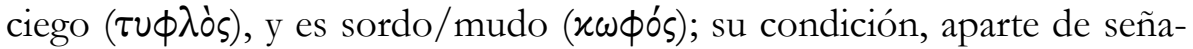
lar el punto más álgido de la incomunicación y la incomprensión (puesto que no recibe ningún tipo de información del exterior a través de la visión o la audición, no puede expresarse a través del habla y, por consiguiente, su corazón, sede de la memoria y los pensamientos, que es alimentado a través de los ojos y los oídos, se encuentra en un estado total de obturación), pone al hombre a merced de las fuerzas del mal (puesto que está poseído por un demonio). En ambos casos, la acción curativa/exorcista de Jesús da pie a que los fariseos afirmen que aquel "expulsa a los demonios por el Príncipe de los demonios” (Mt 9,34; 12,24).

Lucas, por su parte, diferencia lingüísticamente tres ámbitos de comprensión de la mudez; por una parte, al referirse al exorcismo de "un

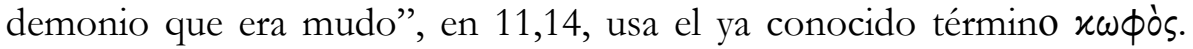
Sin embargo, en 1,20 y 22, cuando señala el estado temporal de mudez de Zacarías ocasionado por no haber creído en las palabras del Ángel

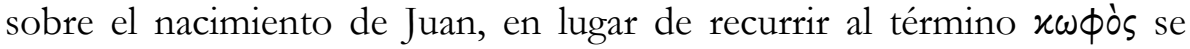

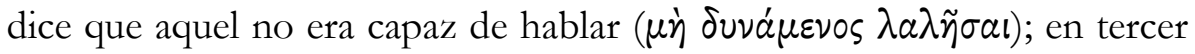
lugar, en el relato de Felipe y el Eunuco de Hch 8,26-40, en el v.32, para referirse al estado mudo de la oveja ante el esquilador de la cita de Is

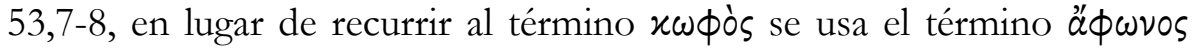
("silencioso", "sin hablar", no porque no tenga la capacidad de hacerlo

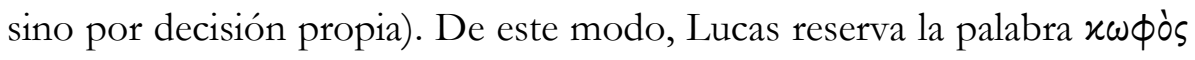
para referirse exclusivamente a quien padece el estado fisiológico (¿demoniaco?) de la mudez y es objeto de la acción liberadora de Jesús. Las demás menciones sobre los sordos/mudos en los evangelios corresponden al ya conocido apotegma de Jesús en que responde a Juan el Bautista sobre su identidad (Mt 11,5 y Lc 7,22). 
Por su parte, en 1Cor 12,2 Pablo emplea el término ä $\phi \omega \nu o s$ para referirse al carácter mudo de los ídolos a los que eran impulsados los Corintios antes de llegar al Evangelio; y recurre a la misma palabra en 1Cor 14,10 , en el contexto de la ponderación del carisma de la glosolalia, para referirse al hecho de que a pesar de la variedad de lenguas que existe en

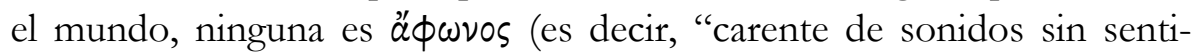
do"). La última referencia sobre la mudez en el corpus epistolar del Nuevo Testamento se encuentra en 2 Pe 2,16 en que el autor trae a colación

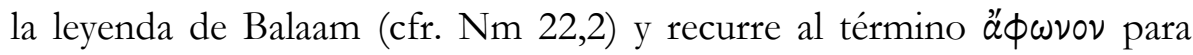
señalar que a pesar de la condición muda natural del asno, este es quien termina hablando con voz humana para frenar "la locura del profeta".

\subsection{Trasfondo socio-cultural y literario en torno a los ciegos y los sordomudos en el mundo judío y greco-romano contemporáneo a la redacción del Nuevo Testamento}

De acuerdo con Collins (2007: 395), en la tragedia griega, entre los pre-socráticos y en las obras de Platón, la ceguera es una metáfora de la ignorancia. En tal sentido, Roig (2014: 186) sostiene que, como un signo humano distintivo, la ceguera ocupa un lugar central en la tragedia griega, especialmente en las obras de Sófocles, en que aquella subraya la falibilidad humana y problematiza la posibilidad del acceso al conocimiento. De hecho, la visión y la intuición humanas son limitadas e imperfectas en comparación con las capacidades perceptivas de una divinidad que ve y entiende todo (Aristóteles, 2007: 1454b). Edipo Rey es quizás la obra en la que esta distinción se aborda más a fondo (Sófocles, 1985). El contraste entre Tiresias, el adivino ciego, y el rey Edipo pone en evidencia dicha distinción puesto que, aunque ciego, debido a su cercana relación con Apolo, Tiresias posee una mayor intuición que Edipo, quien, desconociendo su propia identidad e incapaz de ver la calamidad que enfrenta, aparece como un paradigma de todo ser humano y "ve sin ver" 19 .

De este modo, la habilidad física de ver no implica necesariamente el poseer el don de la intuición o, al menos, una visión más profunda. De modo inverso, cuando el rey finalmente reconoce el atropello que había infligido hacia su padre y su madre, se saca los ojos, quedando ciego; y una vez ciego, es el único que realmente ve: en la culminación de la obra, habiendo alcanzado la intuición de su propia identidad, llega a establecerse como el líder de sus hijos. Además, en Edipo en Colono, el rey ciego

19 De hecho, Edipo se burla de Tiresias por estar "ciego en tus oídos, en tu mente y en tus ojos". El vidente ciego replicó que en realidad era Edipo quien estaba ciego: "Tú puedes ver, pero no puedes ver que estás en dificultades" (Sófocles, 1985: 371 y 413). 
llega a ser clarividente, jugando un rol similar al de Tiresias (MacDonald, 2000: 98). En opinión de Roig (2014: 187), la ceguera de Edipo quizás pudo haber sido más la oportunidad para "volcarse hacia adentro", como un intento de aislar todas las distracciones externas con el fin de enfocarse en sí mismo, como hizo Demócrito, quien, según la tradición, se hizo ciego a sí mismo para intensificar su capacidad reflexiva. El punto es que, desde el trasfondo literario griego, los ojos humanos no solo fallan en garantizar la intuición, sino que pueden intensificar la ceguera. Esto no solo es debido a la falibilidad de los órganos de la visión ${ }^{20}$, lo es especialmente por la intervención de alguna divinidad que puede oscurecer de forma intencional la visión humana. El comienzo del Ajax de Sófocles ofrece un buen ejemplo de ambos aspectos. En relación con la falta de intuición, los ojos de Ajax son testigos inadecuados, y la tragedia muestra qué tanto los dioses pueden llegar a desorientar, oscurecer o simplemente engañar la visión humana en orden a defender sus prerrogativas o castigar a los humanos.

De otro lado, los mitos tradicionales abundan en relatos en los que la ceguera es un castigo para la transgresión humana de los límites entre el mundo de los dioses y el de los hombres. Por ejemplo, en Ajax, una combinación entre ceguera y demencia juega un rol importante en las obras de Eurípides (1991): en Heracles la ceguera y la demencia ocasionan que Heracles mate a sus hijos; y en Bacantes la ceguera y la locura afecta a Agave cuando ataca de forma inadvertida a su propio hijo Penteo quien, a su vez, en un estado de ceguera, no reconoce la divinidad de Dionisio y prohíbe su culto, ocasionando así su muerte cruenta (Roig, 2014: 187; Létoublon, 2010).

Por su parte, en su estudio sobre la relación entre el título "Hijo de David" y el carácter benefactor que tendría Jesús en los evangelios como aquel que otorga la salud, Estévez López (2004: 205) encuentra que en el mundo mediterráneo del siglo I,

La vista es considerada como el mejor de los sentidos, tanto desde un punto de vista material como espiritual. La valoración de que es objeto está en relación con una cultura donde la incapacidad para ver significa la imposibilidad de hacer juicios sobre las cosas. Por tanto, el hecho de tener buena

20 Que podía ser ocasionada naturalmente por alguna deficiencia en la efusión de la luz que, según la teoría pitagórica sobre los fenómenos ópticos, era emitida por los ojos y posibilitaba la visión del mundo exterior (Aguirre, 2012). En el mundo bíblico tal concepción se vería reflejada en expresiones tales como "El ojo es la lámpara del cuerpo. Si tu ojo está sano, todo tu cuerpo estará iluminado; pero si tu ojo está malo, todo tu cuerpo estará a oscuras. Y si la luz hay en ti es oscuridad, ¡Qué oscuridad habrá!” (Mt 6,22-23; ver también Nm 24,3 (LXX); Si 23,19; Dn 10,6).

VERITAS, No 34 (Marzo 2016) 
vista es una de las posesiones más valiosas que una persona mediterránea podía tener en unas sociedades donde el honor se recibe de otros; de ahí que la vida de los ciegos fuera ciertamente difícil, y que la mayoría de la población la catalogaba como una desgracia (...). Sólo en casos excepcionales los ciegos reciben honor.

En el ámbito específico del mundo judío, el marco veterotestamentario abordado permite suponer, como lo hace Guijarro (2000: 108), que Jesús y los primeros cristianos compartían con sus contemporáneos la creencia de que Dios era el origen de la afección y de la salud (Ex 15,26). Aunque las causas de la ceguera o la sordera no son mencionadas en los relatos, es posible presuponer que los Israelitas del siglo primero la atribuían a la influencia de un demonio (Mt 12,22) o quizás a algún pecado personal o heredado (Jn 9,2).

A ello habría que añadir el valor que tiene el sentido de la audición en un contexto en que, según Crossan (2002: 68), "entre el 95 y el 97 por ciento de los contemporáneos de Jesús no sabían leer ni escribir", es decir, en el que la oralidad es casi la única vía para mantener viva la tradición y la memoria del pueblo. En tal ámbito, la condición de sordera de una persona constituiría ipso facto un estado de auto-exclusión con respecto a la responsabilidad social de recibir, mantener y transmitir la identidad cultural de la comunidad humana en la que habita.

Al respecto, van Iersel (1998: 252) considera que una persona sorda es considerablemente menos necesitada de ser conducida hacia Jesús que un paralítico (Mc 2,3) o un ciego (Mc 8,22), aunque en un medio donde prevalece la tradición oral y solo pocas personas son capaces de leer y escribir, la sordera debe ser una invalidez mucho más seria que en una sociedad letrada. Más aún, en un contexto en el que la escucha de la Palabra de YHWH constituye tanto la condición básica de posibilidad para acoger la revelación como el mandamiento principal (Dt 5,1; 6,3-4; 9,1), fuente de las demás regulaciones jurídicas, aquel que carece de la capacidad de escuchar se hace a sí mismo un proscrito con respecto al pueblo y un réprobo con respecto a Dios. Incluso, desde la tradición paulina, si

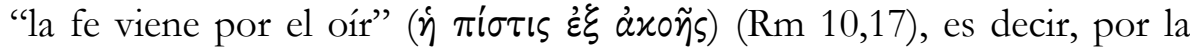
escucha de la predicación apostólica, quien no esté capacitado para oír, difícilmente podrá acceder a la fe; su estructura antropológica interna permanece bloqueada a cualquier revelación y, por ende, a generar una respuesta de fe que, en últimas, le permita alcanzar la salvación.

Para comprender mejor los imaginarios culturales construidos en torno al rol social ejercido por los ciegos y los sordomudos resulta oportuno tener en cuenta el modelo antropológico de "tres zonas" propuesto por Géradon (1958) y retomado por Malina (1995: 97), con el fin de des- 
cribir el modo como era percibido el ser humano desde el trasfondo bíblico. Según dicho modelo, las actividades, estados y conductas de las personas eran distribuidos con relación a tres zonas corporales interconectadas: Una zona del pensamiento emotivo, que funciona a través de los ojos y del corazón (mientras lo propio del corazón es el pensamiento y la memoria, los ojos proporcionan los datos al corazón); una zona de auto-expresión a través del lenguaje, que opera a través de la boca y de los oídos (mientras la boca expresa, a través del habla, los contenidos de la interioridad albergados en el corazón, los oídos captan el lenguaje de los demás) ${ }^{21}$; y una zona de acción deliberada, que encuentra su expresión a través de las manos y los pies (que son los miembros representativos de toda acción) (Malina, 1995: 73-77).

Como afirma Ubieta (2002: 99), "desde esta comprensión de la estructura del ser humano alcanza una mayor significación la mención de las zonas afectadas por la enfermedad, las posesiones o las condiciones de discapacidad, pues nos ayuda a comprender mejor las dimensiones sociales que sufrían alteraciones". Según Guijarro (2000: 108), de estas tres zonas que constituyen al ser humano, la primera era crucial para el conocimiento del individuo en cuanto que los antiguos fisonomistas consideraban el estudio de los ojos como una tarea fundamental para indagar o describir el carácter de una persona. Por tal motivo, los ojos no solo eran un instrumento de la visión sino también el canal de comunicación entre las personas y un modo para acceder a su yo más íntimo. Empero, dichas características estaban bloqueadas para una persona ciega. Además, considerando esta relación muy cercana entre los ojos y el corazón (Ef 1,18), hay que suponer que cuando los ojos estaban cerrados el corazón era incapaz de entender (Jn 12,40; Mt 13,15; Hch 28,27; 1Cor 2,9). De hecho, como observa Guijarro, en Cicerón se afirma que los ojos eran el camino para el corazón (Cicerón, De legigus 1,26-27; Orationes $3,221)$, una creencia que incluso puede ser encontrada en el Antiguo Testamento $^{22}$.

21 Recuérdese, al respecto, el "Himno egipcio a Ptah" en que se dice que "Al igual que todos los sentidos de la vista, del oído y del gusto informan al corazón, y la lengua dice lo que el corazón desea, así también todos los miembros de la Ennéada vinieron a la existencia según los pensamientos del corazón de Ptah y las palabras de la lengua de Ptah” (Mathews \& Benjamin, 2004: 5).

22 Los estudios antropológicos han recalcado que esta insistencia en los ojos y la visión, así como en la dimensión visual de las cosas, es un elemento común en las sociedades mediterráneas, donde el ojo es "un instrumento de conocimiento, poder, depredación, dominancia y sexualidad” (Guijarro, 2000: 108). Por esa razón el mal de ojo es sinónimo de la envidia (Mt 20,15).

VERITAS, No 34 (Marzo 2016) 
Esta percepción sobre el significado y poder del ojo y la visión determina la comprensión que Jesús y sus contemporáneos tenían sobre la ceguera. La persona ciega era, en cierto modo, alguien cuyo acceso al centro de las emociones y pensamientos (el corazón) estaba restringido, tanto desde adentro hacia afuera (deseos, emociones), o desde afuera hacia adentro ("mal de ojo"). La falta de visión la separaría de la interacción social que giraba en torno al honor, ya que el valor y la vergüenza eran valores visuales. Por esa razón, quizás el aspecto más notable de la ceguera era la falta de poder que ello implicaba: Quien no podía ver no podía ejercer control sobre otros ni influir en sus vidas. Estas claves culturales configuran la condición social de la persona ciega (Guijarro Oporto, 2000: 109).

Por su parte, cualquier bloqueo de la zona de auto-expresión, ya fuese por no poder oír (sordera) o no poder hablar (mudez), o por ambos (sordo-mudez), ocasiona, de por sí, una incomunicación en dos niveles: por una parte, el aislamiento del individuo con respecto a su entorno social y, en segundo lugar, la imposibilidad de emitir cualquier tipo de mensaje, no sólo porque no posee la estructura fisiológica adecuada para ello sino porque su entendimiento se encuentra obnubilado ante la ausencia de datos auditivos que deberían llegar del exterior. En últimas, tanto, la ceguera como la sordera, además de ocasionar el bloqueo del corazón, sede de las emociones y del entendimiento, imposibilitan el pleno ejercicio de la zona de acción deliberada ya que sin ver ni oír el obrar resulta torpe, limitado y dependiente.

No se puede ignorar tampoco que según el modelo de Douglas (1980: 80), el cuerpo físico individual es un microcosmos que refleja la situación del cuerpo social. En palabras de Gil Arbiol (2013: 142), “este modelo sostiene que el cuerpo físico, en cuanto que es medio de expresión, funciona como imagen del cuerpo social (...). En este sentido, las partes del cuerpo representan a los miembros de la sociedad y sus obligaciones con respecto a la totalidad de la comunidad". Por tales motivos, Estévez López (1997: 326) afirma que,

Las dolencias sufridas no son entendidas principalmente como disfunciones orgánicas, sino como desvíos de las normas y valores culturales imperantes. Los cuerpos doloridos no son más que el signo patente de una transgresión que amenaza el buen funcionamiento de esa sociedad, expresión de condiciones anormales de vida que hay que atajar cuanto antes y que ratifican la ausencia de protagonismo en la dinámica social.

De acuerdo con dicho modelo, los estados de ceguera y de sordera mencionados en los evangelios no sólo serían condiciones que afectan 
los cuerpos individuales o, como ya se ha dicho, a sus familias, allegados o coterráneos; estos también serían el reflejo a nivel micro-cósmico del estado de ceguera y sordera del cuerpo social al que pertenecen y que se explicaría desde el trasfondo teológico ya abordado como la incapacidad de muchos para reconocer los signos de la irrupción del Reino y la identidad mesiánica de Jesús, siendo torpes o inhabilitados para caminar en pos de Jesús hacia la cruz, y manteniéndose, en últimas, en una situación de exilio.

\section{Conclusiones}

El abordaje del marco histórico-literario en torno al rol y los imaginarios existentes sobre los ciegos y los sordomudos en las tradiciones bíblicas y extra-bíblicas permitió constatar que detrás de tales situaciones subyace la creencia de que esta obturación de los órganos de percepción del pueblo es causada por la infidelidad de este a YHWH (como puede verse Is 6,9-10). La referencia a la Torah (especialmente a textos como Ex 4,11) llevó a entender que así como la visión, la audición y el habla tienen su origen en YHWH, él también es la causa última de la pérdida de estas en todo aquel (tanto individuo como pueblo) que se rebela contra sus designios. De hecho, el pueblo, cuya identidad está determinada por su vocación a "escuchar" la Torah, "ver" la gloria del Dios de la Torah (aspectos que evidencian la existencia de una jerarquización de los órganos de percepción en que la visión y la audición prevalecerían sobre los demás ${ }^{23}$ y "proclamarlas" a las naciones, al desviarse hacia los ídolos de dichas naciones, termina por perder estas facultades y adquiere, por la relación mimética que existe entre un pueblo y su Dios, las características de los ídolos (que no ven, no oyen, no hablan). Esta comprensión será más evidente en la época del exilio en que la lejanía de la tierra será análoga a la lejanía de la Alianza, condiciones que dificultan y hasta imposibilitan la visión de la gloria del Dios de Israel. En contraposición, los signos escatológicos del regreso corresponden a la reivindicación y curación de aquellos que han padecido la invalidez (Is 35,1-10); ellos no sólo verán u oirán como antes sino que también serán capaces de comprender y anunciar los misterios de Dios.

De igual manera, a pesar de haber encontrado unos pocos casos de reconocimientos especiales hacia los ciegos y los sordos a quienes se les

23 Al respecto, Lammers (1967: 128) constata que "los sentidos preponderantes son los dos más elevados, oír y ver. Se presentan como los verdaderos órganos receptores de la revelación divina. Con mucha frecuencia los encontramos unidos. De todos modos, el tacto puede aparecer también como una forma de experimentar la salvación".

VERITAS, No 34 (Marzo 2016) 
adjudicaba algún tipo de intuición o clarividencia como compensación divina por su condición ( $\mathrm{O}$, al menos, se enaltecía su capacidad reflexiva en contraste con la falibilidad de quienes poseían todos sus sentidos físicamente inalterados), esta aproximación puso en evidencia el carácter prevalentemente marginal, aislado y vulnerable al que estos, entre otros discapacitados, se veían sometidos con respecto a la vida social, política y cúltica de Israel. Esta era una realidad de vergüenza y deshonor, intensificada por la creencia social de que su situación era un castigo divino por algún pecado cometido (y que, por ello, podía involucrar la intervención de alguna entidad demoniaca), que no sólo les afectaba a ellos como individuos sino que también repercutía en su entorno familiar y social.

Además, la escisión que las condiciones de ceguera o sordera generaban en la estructura antropológica de quienes las padecían imposibilitaba cualquier comunicación, y posterior reflexión, de las impresiones y estímulos provenientes del mundo exterior hacia el corazón (zona del pensamiento emotivo), la exteriorización verbal de los contenidos de la interioridad albergados en el corazón (zona de auto-expresión) y la realización plena e independiente de la propia decisionalidad debido a la incertidumbre sobre la realidad del entorno (desconocido o parcialmente conocido) y los juicios fragmentados emitidos sobre aquel (zona de acción deliberada). Dicha escisión se vería agravada al considerar la realidad del cuerpo individual (en términos de "afección" y "padecimiento") como un reflejo, a nivel micro-cósmico, de la situación del cuerpo social al que pertenece (en términos de "mal"). Así, los individuos ciegos y sordos presentados en el evangelio no serían más que una representación a escala de la ceguera de muchos que no han sido capaces de reconocer la irrupción del Reino de Dios y la identidad mesiánica y divina de Jesús.

De este modo, en los evangelios, la acción taumatúrgica-exorcista de Jesús al restaurar a los ciegos y a los sordomudos, además de revelar la llegada del tiempo escatológico que da por finalizado tanto el exilio de Israel como el gobierno de Satanás sobre el mundo, muestra el carácter inclusivo, reivindicativo y "descontaminante" del Reino de Dios que está irrumpiendo a través de la reinserción social de las personas (tanto individuales como colectivas) mediante la recomposición del entramado de sus relaciones y la integración de su ser interior dividido, haciéndoles capaces de ver el poder de Dios actuando a través de Jesús, de escuchar la Palabra de Dios, de ponerla por obra y anunciarla a las naciones.

\section{REFERENCIAS}

-Aguirre, J. (2012). La crítica de Aristóteles y Teofrasto a la concepción ígnea del ojo. Emerita (80), 89-106. 
-Allison, D. (2000). The Intertextual Jesus: Scripture in Q. Harrisburg: Trinity Press International.

-Andiñach, P. (2012). Introducción hermenéutica al Antiguo Testamento. Estella: Verbo Divino.

-Aristóteles. (2007). Arte poética. Arte retórica. México, D.F.: Porrúa.

-Ubieta, C. (2002). La curación del endemoniado de Gerasa desde la antropología cultural. En R. Aguirre Monasterio (Ed.), Los milagros de Jesús: Perspectivas metodológicas plurales (pp. 93-120). Estella: Verbo Divino.

-Boase, E. (2001). Life in the Shadows: The Role and Function of Isaac in Genesis - Syncronic and Diachronic Readings. Vetus Testamentum (51), 312335.

-Collins, A. (2007). Mark: A Commentary. Minneapolis: Fortress.

-Crossan, J. (2002). El nacimiento del cristianismo: Qué sucedió en los años inmediatamente posteriores a la ejecución de Jesús. Santander: Sal Terrae.

-Douglas, M. (1980). Símbolos naturales. Madrid: Alianza editorial.

-Dunn, J. (2009). El cristianismo en sus comienzos. Tomo I: Jesús recordado. Estella: Verbo Divino.

-Estévez, E. (1997). «Y todos los que lo tocaban quedaban sanados»: El cuerpo como espacio de gracia. Sal Terrae (100), 323-336.

-Estévez, E. (2004). Jesucristo, Hijo de David y benefactor que otorga la salud: La curación de los ciegos de Jericó (Mt 20,29-34). En S.Castro, F. Millán \& P. Rodríguez Panizio (Eds.), Umbra, Imago Veritas: Homenaje a los profesores Manuel Gesteira, Eusebio Gily Antonio Vargas-Machuca (pp. 183-222). Madrid: Publicaciones de la Pontificia Universidad de Comillas.

-Eurípides (1991). Tragedias. Madrid: Gredos.

-Géradon, B. De. (1958). L'Homme à l'image de Dieu. Nouvelle Revue Théologique (80), 683-695.

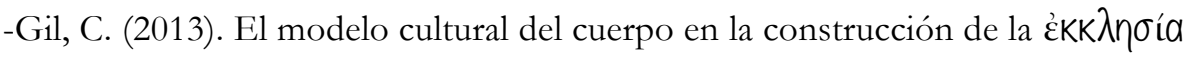
paulina. En R. Aguirre Monasterio (Ed.), El Nuevo Testamento en su contexto: Propuestas de lectura (pp. 141-155). Estella: Verbo Divino.

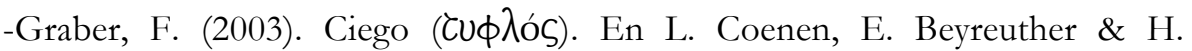
Bietenhard (Ed.), Diccionario Teológico del Nuevo Testamento (Vol. I; pp. 261262). Salamanca: Sígueme.

-Guijarro, S. (2000). Healing Stories and Medical Anthropology: A Reading of Mark 10:46-52. Biblical Theology Bulletin: A Journal of Bible and Theology (30), 102-112.

-Habel, N. (1965). The Form and Significance of the Call Narratives, Zeitschrift für die Alttestamentliche Wissenschaft (77), 297-323.

-Hull, J. (2007). Dios ciego, Biblia ciega: Una lectura de la Biblia desde la experiencia de oscuridad. Buenos Aires, Lumen.

-Iersel, B. van. (1998). Mark: A Reader-Response Commentary. Sheffield: Sheffield Academic Press.

-Lammers, K. (1967). Oír, ver y creer según el Nuevo Testamento. Salamanca: Sígueme. 
-León, J. L. De. (2011). 'Yo soy Yahvé, el que te sana' (Ex 15,26): enfermedad y salud en la Torá. Theologica Xaveriana (171), 65-96.

-Létoublon, F. (2010). To See or Not to See: Blind People and Blindness in Ancient Greek Myths. En M. Christopoulos, E. Karakantza \& O. Levaniouk (Eds.), Light and Darkness in Ancient Greek. Myth and Religion (pp. 167180). Lanham: Lexington Books.

-MacDonald, D. (2000). The Homeric Epics and the Gospel of Mark. New Haven London: Yale University Press.

-Malina, B. (1995). El Mundo del Nuevo Testamento: Perspectivas desde la antropología cultural. Estella: Verbo Divino.

-Marcus, J. (2010a). El evangelio según Marcos (Mc 1-8). Salamanca: Sígueme.

-Marcus, J. (2010b). El evangelio según Marcos (Mc 8-16). Salamanca: Sígueme.

-Mathews, V. \& Benjamin, D. (2004). Paralelos del Antiguo Testamento: Leyes y relatos del antiguo oriente. Santander: Sal Terrae.

-Meynet, R (2012). Una nueva introducción a los evangelios sinópticos. Miami: Convivium Press.

-Olyan, S. (2001). The Exegetical Dimensions of Restrictions on the Blind and the Lame in Text from Qumran. Dead Sea Discoveries (8), 38-50.

-Rahlfs, A. (2006). Septuaginta: Id est Vetus Testamentum graece iuxta LXX interpretes. Stuttgart: Deutsche Bibelgesellschaft.

-Roig, L. (2014). Blindness. En H. Roisman (Ed.) The Encyclopedia of Greek Tragedy. Vol. 1 (pp. 186-187). Southern Gate: Wiley-Blackwell.

-Schneider, G. (2001a). KwфóS, Kophos, mudo; sordo. En H. R. Balz \& G. Schneider (Eds.) Diccionario Exegético del Nuevo Testamento (Vol II; p. 2454). Salamanca: Sígueme.

-Schneider, G. (2001b). ¿uф入ós, Thyphlos, ciego. En H. R. Balz \& G. Schneider (Eds.) Diccionario Exegético del Nuevo Testamento (Vol I; pp. 1812-1816). Salamanca: Sígueme.

-Sicre, J. L. (2011). Introducción al Antiguo Testamento. Estella: Verbo Divino.

-Sófocles (1985). Tragedias completas. Madrid: Cátedra.

-Wilson, B. (2014). The Blinding of Paul and the Power of God: Masculinity, Sight, and Self-Control in Acts 9. Journal of Biblical Literature (133), 367-387.

Sumario: Introducción; 1. Trasfondo hermenéutico sobre la comprensión de la ceguera y la sordera en el Antiguo Testamento; 1.1 Ciegos y ceguera en la TaNaK y en la Septuaginta; 1.2 Sordos y sordera en la TaNaK y en la Septuaginta; 1.3 Connotaciones teológicas de la ceguera y la sordera en el Antiguo Testamento; 2. Comprensiones sobre la ceguera y la sordera en el Nuevo Testamento; 2.1 Rastreo de campos semánticos en el Nuevo Testamento; 2.1.1 Campos semánticos sobre ciegos y ceguera; 2.1.2 Campos semánticos sobre sordos, mudos, sordera y mudez; 2.2 Trasfondo socio-cultural y literario en torno a los Ciegos y los Sordomudos en el mundo judío y grecoromano contemporáneo a la redacción del Nuevo Testamento; Conclusiones; Referencias. 